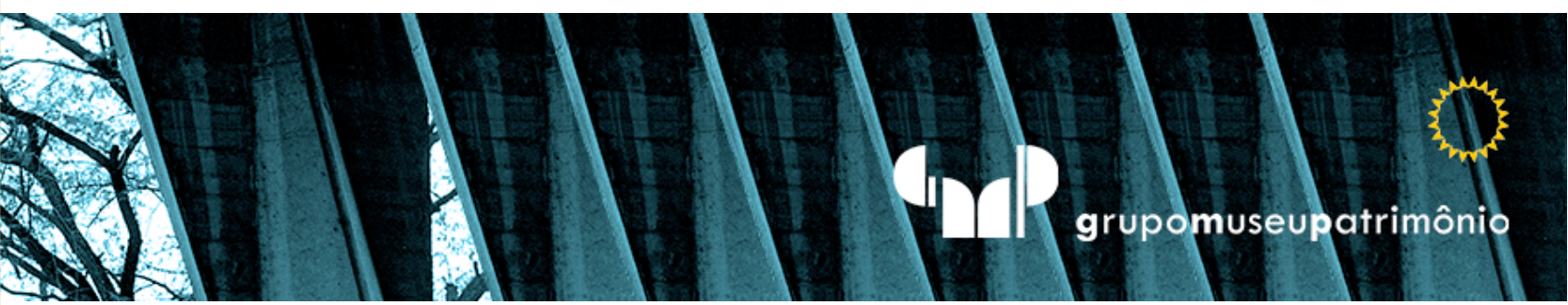

\title{
A derrubada de cada estátua é um apelo
}

\author{
El derrocamiento de cada estatua \\ es un atractivo
}

\section{The overthrow of each statue is an appeal}

\begin{abstract}
Anna Maria Abrão Khoury Rahme
Pesquisadora do Grupo Museu/Patrimônio. Faculdade de Arquitetura e Urbanismo da Universidade de São Paulo. São Paulo. Brasil. annarahme@gmail.com
\end{abstract}




\title{
Resumo
}

O artigo aborda aspectos que envolvem a manutenção patrimonial ou a demolição sumária dos ditos monumentos honoríficos, a inserir observações críticas nos debates sobre a derrubada das estátuas e selecionar como objeto de estudos duas obras - ambas denunciadas por alguns grupos como elegias ao escravismo brasileiro - de autoria de Júlio Guerra: Borba Gato e Mãe Preta, examinadas sob a ótica das ideias de Georges Didi-Huberman a respeito das imagens.

Palavras-Chave: Memória. Representação. Sintoma. Estátuas. Reconfiguração. São Paulo. Pandemia.

\section{Resumen}

El artículo analiza aspectos que implican el mantenimiento del patrimonio o la demolición sumaria de los llamados monumentos honoríficos, la inserción de observaciones críticas en los debates sobre el derrocamiento de las estatuas y la selección como objeto de estudios dos obras -ambas denunciadas por algunos grupos como elegías a la esclavitud brasileña- escritas por Júlio Guerra: Borba Gato y Mãe Preta, examinadas desde la perspectiva de las ideas de Georges Didi-Huberman sobre las imágenes.

Palabras clave: Memoria. Representación. Síntoma. Estatuas. Reescribir. São Paulo. Pandemia.

\begin{abstract}
The article discusses aspects that involve the maintenance of heritage or the summary demolition of the so-called honorific monuments, inserting critical observations in the debates about the overthrow of the statues and selecting as the object of studies two works - both denounced by some groups as elegias to Brazilian slavery - authored by Júlio Guerra: Borba Gato and Mãe Preta, examined from the perspective of Georges Didi-Huberman's ideas about the images.
\end{abstract}

Keywords: Memory. Representation. Symptom. Statues. Rewrite. São Paulo. Pandemic. 


\title{
INTRODUÇÃO
}

\begin{abstract}
"Com frequência, quando pousamos nosso olhar sobre uma imagem de arte, vemnos a irrecusável sensação do paradoxo [...] Podemos aceitá-lo, nos deixar levar por ele; podemos mesmo experimentar certo gozo em nos sentirmos alternadamente cativos e liberados nessa trama de saber e de não-saber, de universal e de singular, de coisas que pedem uma denominação e coisas que nos deixam de boca aberta [...]" (DIDI-HUBERMAN, 2020 [1990], p. 9)
\end{abstract}

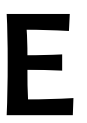
scritas por Georges Didi-Huberman, em seu livro Diante da imagem, essas ideias soam incrivelmente atuais se nos detivermos sobre o que nos seduz ou nos causa aversão numa obra de arte. Certamente não é uma questão de gosto. Trata-se de uma experimentação individual que põe em dialética o olhar e o ver, o saber e o não saber, ressuscitados pelo inconsciente - como estabeleceu Sigmund Freud - e que determinam os sintomas, remetendo-nos a "conceitos tais como posterioridade [après-coup], a repetição, a deformação e a perlaboração" (DIDIHUBERMAN, 2020, p. 15). Porém, se tais estudos nos remetem ao sujeito, também se referenciam ao objeto da arte, as imagens, por sua apresentabilidade e/ou representabilidade, respectivamente, o trabalho do que se manifesta pelo visivel e do que se manifesta pelo legível (p. 16). 
Estabelecem, portanto, parâmetros para a abordagem da História da Arte como conhecimento crítico, instaurando mais dúvidas que certezas e mais síntese que análises. De algum modo, introduzem questionamentos à natureza da imagem - sua idealização, produção, imposição, multiplicação -, sugerindo novas formas possíveis e desejáveis. Essa busca por mudanças explica o vínculo ao movimento pela derrubada das estátuas revelado com a saída às ruas em inúmeras cidades nos mais diferentes países, em plena pandemia da Covid-19, durante três semanas no mês de junho de 2020.

A divulgação maciça das manifestações acirrou ânimos e pôde-se assistir, às vezes em tempo real, a reiterados atos de insubmissão às forças e ordens oficiais. Em poucos dias, os protestos ampliaram-se em demandas, entre as quais o fim de tudo o que possa recordar a opressão social, venha de onde ou de quem vier. As "palavras de ordem" pelo trajeto ou os discursos proferidos em locais dos ajuntamentos apelam pela decolonização e nomeiam cada fato, instituição, movimento ou grupo que os violenta.

Enquanto, no mundo inteiro, estas ações cresciam numericamente, ampliando-se com a pichação ou destruição de monumentos que representam a antítese da luta atual, no Brasil, as altas taxas de infectados pela Covid-19 naqueles dias reduziram a tímidas aparições ${ }^{1}$ nas ruas, terminando contidas pela truculência das forças policiais, as mesmas que acompanharam e protegeram manifestantes pró-governo. Assim sufocados e diante da impossibilidade atual de organizar-se nacionalmente, alguns grupos envolvidos iniciaram por reforçar as demandas regionais, escancarando - em vídeos feitos por celulares e divulgados na Internet - as ações de repressão e espancamento dos moradores das periferias pelas polícias militar e civil.

Note-se que a maioria das vítimas são homens pretos jovens residentes em bairros pobres da cidade de São Paulo, não por coincidência, as zonas mais contaminadas pela atual pandemia. Nessas circunstâncias, os debates sobre as esculturas no espaço público ganham menor destaque na mídia, embora não menor importância,

\footnotetext{
${ }^{1}$ Nesses meses, grupos de torcidas organizadas oriundos de vários times de futebol brasileiros, vestindo orgulhosamente suas camisas, lançaram gritos de guerra nas avenidas e passeios em diversas cidades Porto Alegre, Belo Horizonte, São Paulo, Rio de Janeiro, Recife entre outras -, com táticas idênticas às usadas nos estádios, agora clamaram pelo direito à igualdade e liberdade como cidadãos brasileiros.
} 
já que a discussão levanta pontos fundamentais sobre "quem são nossos heróis" e "quais os fatos rememorados" nos monumentos urbanos. Ressurge entre nós o antigo assunto a respeito da relevância na ocupação das áreas públicas pela implantação de marcos com os quais a população não se identifica, ou seja, que não fazem parte de sua memorialidade.

Apesar do esmorecimento das manifestações, é primordial repensar a matéria e trazer enfoques consonantes e dissonantes às opiniões agora vindas à tona, relacionar os últimos acontecimentos a outros não tão recentes, fomentar argumentações sobre o assunto, fazer emergir pautas, ouvir a pluralidade de opiniões, dialogar e procurar soluções representativas, mesmo que não sejam definitivas. E, mais ainda, "buscar o discurso que se proclama ele próprio enquanto saber sobre a arte, arqueologia das coisas esquecidas ou não percebidas nas obras desde sua criação" (DIDI-HUBERMAN, 2020, p. 9), na esteira do que Georges Didi-Huberman chama de representação e aquilo que nos é "simplesmente apresentado" (2020, p. 9).

O presente artigo destaca para análise duas polêmicas peças do escultor Júlio Guerra: Borba Gato (1962) e Mãe Preta (1954); lança o olhar de pesquisadora da "escultura nos espaços públicos de São Paulo" ${ }^{2}$, sobre questões formuladas ou não em outros artigos publicados, diálogos ao vivo na Internet - ditos lives -, palestras, colunas em periódicos e entrevistas. Para tanto, fundamenta-se na apreciação das esculturas pela materialização, implantação, representação e ressignificação ${ }^{3}$, trazendo elementos teóricos e filosóficos que propõem observar a obra de arte a partir de um conjunto de visibilidades dadas pelo conhecimento da história de sua produção, até nossos dias, quando fatores de apreciação - abrangência e potencialidades - são acrescidos e/ou modificados.

\footnotetext{
${ }^{2}$ Entre as pesquisas de maior importância, desde os anos 1990, estão: Imagens femininas em memória à vida: a escultura nos cemitérios da Consolação, Araçá e São Paulo, de 1900 a 1950 (2000) e Inovar e conservar: a ambiguidade no Monumento constitucionalista (2005), respectivamente, Dissertação de Mestrado e Tese de Doutorado, ambas orientadas pela Profa. Dra. Maria Cecília França Lourenço na FAUUSP.

${ }^{3}$ No texto optou-se pelo uso de itálico para designar termos/conceitos importantes para as questões abordadas no artigo. Além dos casos previstos (título de obras e palavras estrangeiras) aparecem também em itálico os grifos mantidos nas citações feitas pelo próprio autor citado.
} 
Debruça-se, ainda, sobre o fato dos debates acerca esculturas nos espaços públicos ressurgirem como tema, evidenciando as construções e os apagamentos nos discursos, obrigando-nos a romper a caixa da representação, como prega Georges Didi-Huberman após afirmar que "entre saber e ver" trata-se de um processo dialético: "pensar a tese com a antítese, a arquitetura com suas falhas, a regra com sua transgressão, o discurso com seu lapso, a função com sua distinção (mais além de Cassirer, portanto), ou o tecido com sua rasgadura" (2020, p. 190).

Apropriando-se do termo rasgadura, numa "aproximação para renunciar ao idealismo da história da arte" (DIDI-HUBERMAN, 2020, p. 212), Didi-Huberman introduz o conceito de sintoma:

\begin{abstract}
Por que afinal chamar de sintoma essa potência de rasgadura? Sintoma nos diz a escansão infernal, o movimento anadiômeno do visual no visível e da presença na representação. Diz a insistência e o retorno do singular no regular, diz o tecido que se rasga, a ruptura de equilíbrio e o equilíbrio novo, o equilíbrio inédito que logo vai se romper. $\mathrm{E}$ o que ele diz não se traduz, mas se interpreta, se interpreta sem fim. (2020, p. 212-3)
\end{abstract}

Esse movimento contínuo promove aquilo que o autor chama de sobrevivência da imagem -- "ao mesmo tempo soberana e rastro de apagamento" --, baseada na "força da omissão ou da supressão de que é, estritamente falando, o vestígio" (DIDIHUBERMAN, 2020, p. 194).

\title{
SOMOS TODOS OUTROS
}

"[...] as emoções têm um poder - ou são um poder - de transformação. Transformação da memória em desejo, do passado em futuro, ou então da tristeza em alegria."4 (DIDI-HUBERMAN, 2018, p. 44)

Georges Didi-Huberman traduziu antecipadamente as conquistas dos movimentos de rua, cujos brados por transformações têm brotado pelas emoções coletivas e vêm mobilizando multidões, desde meados de maio de 2020, pela demolição dos modos de opressão e de racismo estabelecidos, desde sua eclosão a partir do assassinato de

\footnotetext{
${ }^{4}$ Palestra sobre as emoções proferida em Montreuil, França, a 13/04/2013.
} 
George Floyd ${ }^{5}$, um cidadão preto estadunidense, pela polícia de Nova lorque. Embora lideradas pelo movimento Black Lives Matter ${ }^{6}$, as manifestações não se restringiram à demanda racial, se desdobraram em pleito pela vida, a vida de todos sem exceção, apesar das diferenças, e nada mais impactante do que perceber nas ruas a esmagadora pluralidade de grupos ali representados. Afinal, somos todos outros!

A diversidade estratégica das lutas foi se modificando à medida que avançavam em petições e exigências locais e/ou universais, fazendo germinar, quase naturalmente, um movimento pela derrubada de estátuas que imortalizam escravagistas e conquistadores, pela decolonização. Revive-se hoje fatos similares àqueles pela descolonização, em 1975, na pós-Independência da África do domínio português, quando a população decidiu eliminar drasticamente as figuras celebradas nos espaços públicos durante o colonialismo.

Passando por uma ruptura histórica, os movimentos de libertação se viram compelidos a considerar uma nova memória coletiva, então constituída, e derrubar os heróis impostos pelo antigo regime. Iniciada a destruição, total ou parcial, dos tributos, surgiram questões envolvendo patrimônio, preservação, exposição e recepção, implicando em decidir entre preservar as ruínas ou os vestígios e permitir a sobrevivência ou segunda vida. A experiência somou conhecimento, resultando em propostas como o encaminhamento de obras para a musealização, o reposicionamento ou, até mesmo, a permanência nos locais de implantação com a obrigatoriedade de aferir mudanças semânticas em suas placas de identificação ${ }^{7}$.

Naquelas circunstâncias ou nas atuais, a depredação dos monumentos - esses sinais do passado que recolhem traços de uma cultura material da memória coletiva - é a

\footnotetext{
${ }^{5}$ George Floyd, identificado nos Estados Unidos como afro-americano, morreu por asfixia em 25 de maio de 2020, após um policial da cidade de Minneapolis, Derek Chauvin, ter ajoelhado em seu pescoço até sufocá-lo.

${ }^{6}$ O movimento internacional Black Lives Matter (Vidas Negras Importam) tem origem na comunidade afro-americana, USA, e foi fundado a 13 de julho de 2013 pelas ativistas Alicia Garza, Patrisse Cullors e Opal Tometi.

${ }^{7}$ As informações encontram-se em "Monumentos coloniais em tempos pós-coloniais: o Monumento a Mouzinho de Albuquerque após o fim do Império", s. a. Paper-Cloud, do IV Congresso de História da Arte Portuguesa realizado pela Fundação Calouste Gulbenkian, de 21-24/11/2012, publicado em 26-10-2017.
} 
tática eleita pelos que contestam sua representatividade. Trazer esses marcos para o centro dos debates atuais reflete avaliar o quanto eles são instrumentos de poder, desde o projeto, passando pelas condições de construção, pela manipulação da simbologia e perenização dos valores inicialmente postos. Nossos tempos clamam por mudanças, as revolucionárias, que desestruturem essa memória construída e fundem novas "condições de produção dos documentos-monumentos", aquelas capazes de mudar a história demolindo essa "montagem" (LE GOFF, 1990, p. 549).

Exemplarmente, Bristol, na Inglaterra, registrou, no dia 7 de junho, um dos primeiros atos por uma multidão enfurecida que apeou de seu pedestal a estátua de Edward Colston (1895) e a jogou no rio da cidade. Um mês depois, em 15 de julho, sobre o mesmo pedestal implantou-se a escultura do artista Marc Quinn, retratando uma ativista negra, Jen Reid (Figura 1), referenciando-a, pelos gestos e boné, à força e liderança femininas presentes em A Liberdade Guiando o Povo, pintura de Eugène Delacroix, em comemoração à Revolução de Julho de 1830. A escultura representando uma moradora do bairro engajada no Black Lives Matter resistiu apenas algumas horas antes de ser retirada, enquanto a anterior, enaltecendo um alto funcionário da Royal African Company do final do século XVII que enviou 80.000 pessoas da África Ocidental escravizadas para a América, havia permanecido em praça pública por 125 anos. 


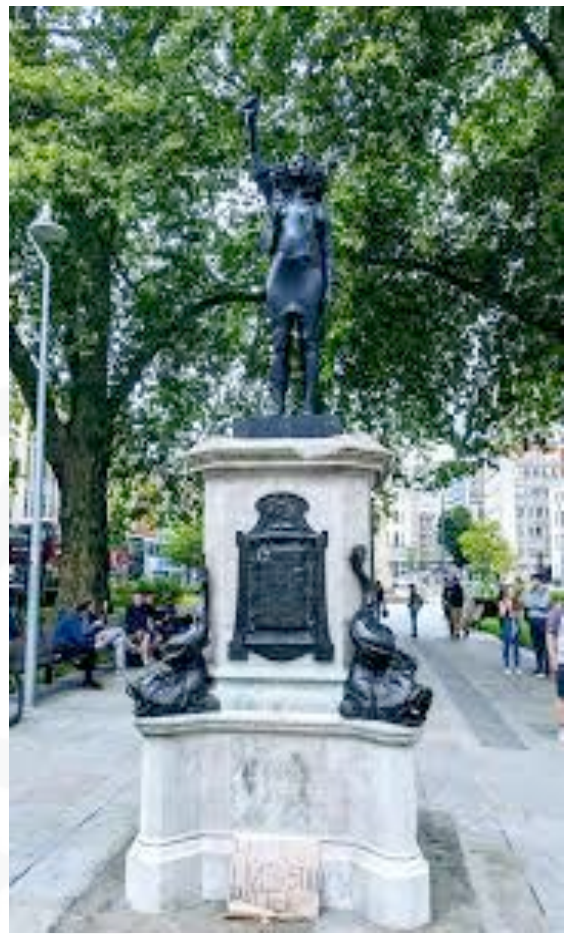

Figura 1: Estátua de Jen Reid substitui a de Edward Colston, Bristol, Inglaterra, 7 jun. 2020. Fonte: Foto Alex Richards.

\section{DIFERENTES PRÁTICAS A CADA MOMENTO}

"[...] a imagem não é um simples corte praticado no mundo dos aspectos visíveis. É uma impressão, um rastro, um traço visual do tempo que quis tocar, mas também de outros tempos suplementares - fatalmente anacrônicos, heterogêneos entre eles - que, como arte da memória, não pode aglutinar". (DIDIHUBERMAN, 2015 [1996], p. 207)

Manter ou retirar do espaço público um monumento vai além dos desejos de grupos que se mantêm alijados do caráter da imagem, que difere de "um simples corte praticado no mundo dos aspectos visíveis" (DIDI-HUBERMAN, 2015, p. 207) e não pode ser guardada como algo imóvel, intocável, e de tempos em tempos ser retirada do esquecimento e reviver com os mesmos valores simbólicos. Mas, congrega em si "outros tempos suplementares - anacrônicos, heterogêneos entre eles" (Idem) e persiste como um rastro, distinto da perenização que exige ações constantes para promover seu pertencimento a uma dada população. 
Outro fator considerável é a dinâmica do lugar dada pelo conjunto de modificações impressas e que são desprezadas nos momentos em que o poder público se apossa dos monumentos urbanos, iluminando-os ou equipando-os com adereços alusivos às datas, como ocorre com o governo estadual e a prefeitura da capital paulista. Uma dessas alianças se deu em 2002, quando o Movimento Outubro Rosa, em campanha anual de combate ao câncer de mama, inaugurou uma nova tipologia de espetacularização, iluminando de rosa o Monumento e Mausoléu ao Soldado Constitucionalista de $32^{8}$, do Parque Ibirapuera (RAHME, 2005). Curiosamente, a cada 9 de julho, a mesma esplanada é ocupada por tropas e armas do II Exército e Polícia Militar desfilando em comemoração àquele que se tornou historicamente conhecido como um movimento de insurgência paulista contra a Federação.

Igualmente alinhado ao parque o Monumento às Bandeiras ${ }^{9}$, idealizado por Victor Brecheret (1894-1955) para ser erigido em comemoração ao Centenário da Independência (1922) e inaugurado apenas em 1953, é mais um marco preferencialmente eleito. Tido como um "cartão postal de São Paulo" retrata a saída da tropa em direção ao Oeste - "para desbravar os sertões do Brasil", como habitualmente se consagrou. O termo "bandeirante" personifica o líder colonizador, comandante das Entradas e Bandeiras, cujo ponto de partida ficava em território paulista, que por isso passou a ser conhecida como "terra bandeirante". A figura homônima adjetiva parte do solo pátrio, batiza ruas, avenidas e estradas, além de nomear o órgão repressor paulista, a Operação Bandeirante (1969), responsável por

\footnotetext{
${ }^{8}$ O Monumento e Mausoléu ao Soldado Constitucionalista de 32, conhecido como Obelisco do Ibirapuera, foi projetado por Galileo Emendabili (1898-1974) e teve sua implantação iniciada em 1947, inaugurado em 1955 e finalizado em 1970. Construído num terreno de 1932 metros doado pela Prefeitura do Município e por particulares identificados com a chamada Revolução de 32, como querem lembrar os grupos que o edificaram. Ver mais na Tese de Doutorado da autora, depositada na FAUUSP. Foi tombado pelo CONDEPHAAT como Patrimônio Cultural Paulista em 09/07/81, Processo 20294/77.

${ }^{9}$ A maquete em gesso do Monumento às Bandeiras " [...]foi exposta ao público em 28 de julho de 1920, acompanhada de um memorial explicativo, na Casa Byington, na 26, Rua 15 de Novembro, n. 26, sendo matéria de vários jornais de São Paulo" (PECCININI, 2004, p. 42). Apenas em 1936, tendo reformulado o projeto Victor Brecheret o apresentou a Armando Salles de Oliveira, interventor no Governo do Estado de São Paulo, que autorizou a montagem de um galpão de obras para a execução do monumento reunindo uma equipe de escultores, entre os quais estava Júlio Guerra. Foi tombado pelo CONDEPHAAT como Patrimônio Cultural Paulista em 07/05/85, Processo 23074/84.
} 
perseguir, aprisionar e torturar todo suspeito de se opor à ditadura militar (RAHME, 2018) (Figura 2).

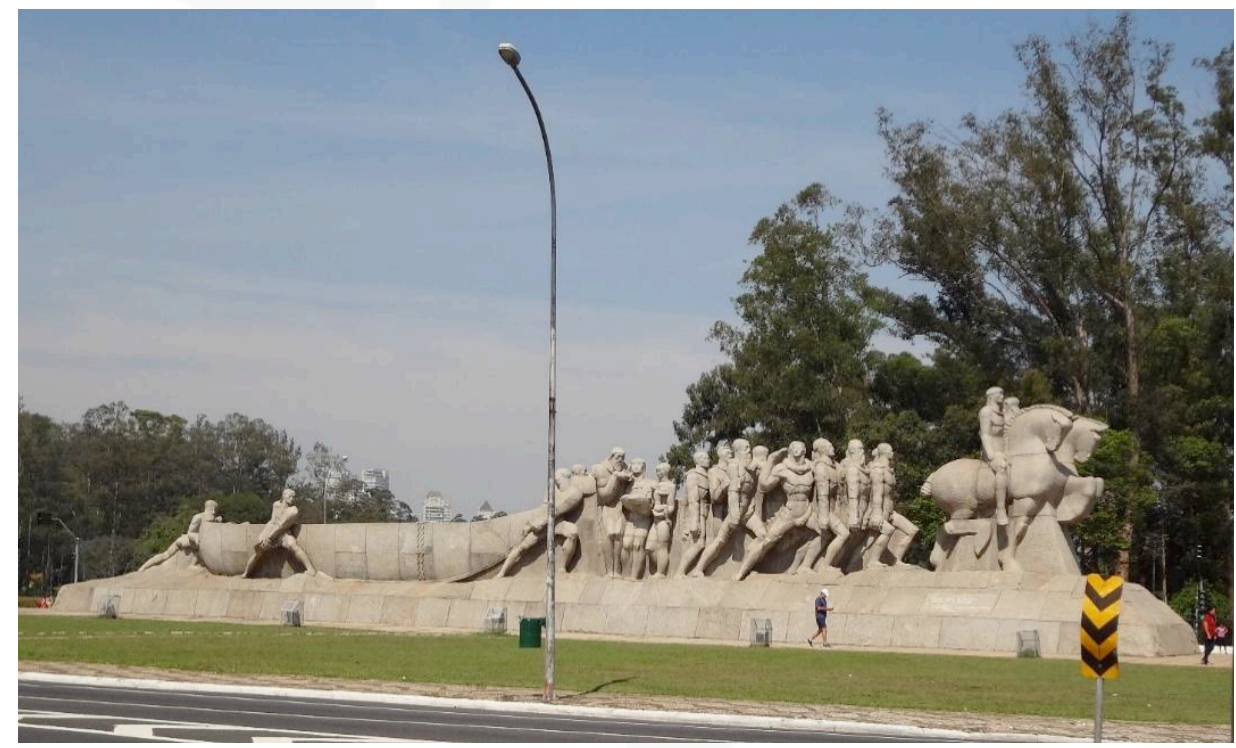

Figura 2: Monumento às Bandeiras (1920-1953), Victor Brecheret. Parque Ibirapuera, São Paulo, SP. Fonte: Foto da autora, jun. 2020.

Situado estrategicamente na praça Armando Salles de Oliveira, na confluência entre as avenidas Pedro Álvares Cabral e Brigadeiro Luís Antônio, tem os contornos do perfil destacado em contraste com o bosque de eucaliptos ao fundo e uma volumetria irregular de figuras masculinas em marcha, visível na sua totalidade tridimensional pela circunscrição da rotatória. Essa cenografia o torna foco de eventos e acontecimentos, reforçando a consagração como símbolo da cidade, uma imagem que fica bem na foto, seja em postais, cenas de casamento, campanhas sanitaristas - combate à AIDS, combate ao câncer de mama, uso de mascaras como proteção à Covid-19 - ou nas intervenções dos artistas urbanos (Figura 3). 

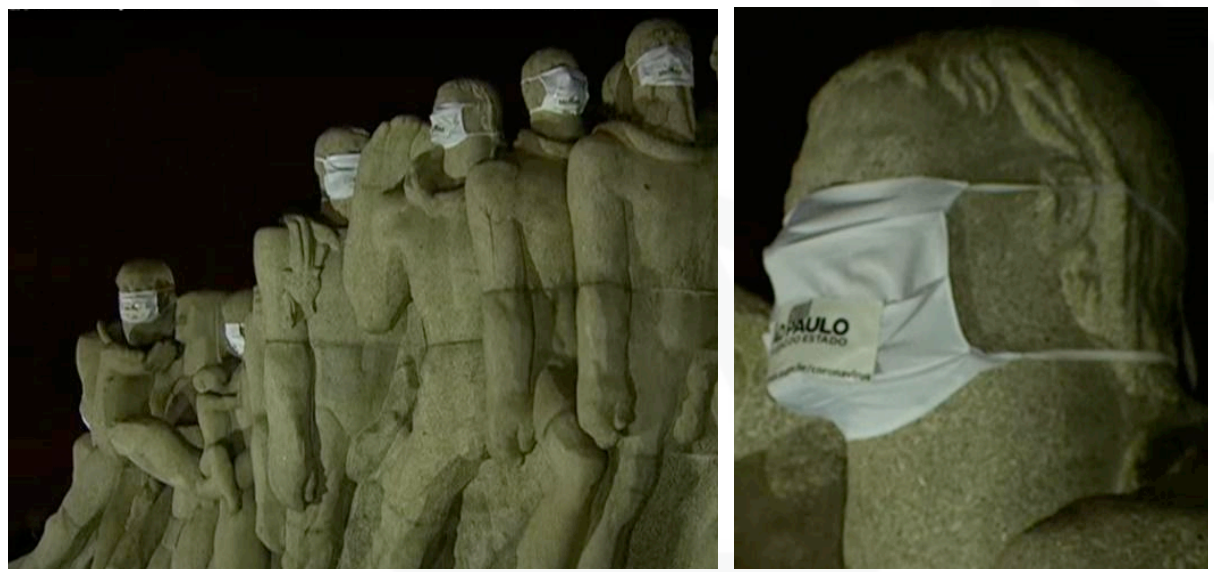

Figuras 3: Detalhes do Monumento às Bandeiras (1920-1953), Victor Brecheret. Parque Ibirapuera, São Paulo, SP. Fonte: Fotos da autora, maio 2020.

Apesar das recorrentes tentativas de apropriação, o monumento segue cercado pela aura do lugar e da representação à qual se destinou, "homenagear os heróis paulistas", conforme anunciam inscrições nas duas faces laterais do pedestal. À direita, "Brandiram achas e Empurraram quilhas / Vergando a vertical de Tordesilhas", de Guilherme de Almeida (1890-1969), que participou do Movimento Constitucionalista de 32 e, como heraldista, criou os brasões-de-armas para diversas cidades, entre elas São Paulo (SP) e Brasília (DF). À esquerda, "Glória aos Heróis que traçaram / O nosso destino na geografia / Do mundo livre, / Sem eles o Brasil não seria grande como é", de Cassiano Ricardo (1894-1974), escritor do livro Marcha para Oeste (1940), a respeito do movimento das entradas e bandeiras. Em comum, além da poesia, os autores desses versos foram engajados no Movimento Modernista, advogados formados pela Faculdade de Direito do Largo São Francisco, membros da Academia Paulista de Letras e Academia Brasileira de Letras.

Recentemente pôde-se testemunhar idêntica apropriação operada sobre monumentos menores, mas não menos expressivos para as comunidades locais, na propagação da campanha de prevenção contra a Covid-19. A partir do mês de abril, uma verdadeira empreitada expandiu as fronteiras das grandes capitais brasileiras até cidades de menor porte. Para ficar apenas em uma delas, $\mathrm{Itu}^{10}$, no interior

\footnotetext{
${ }^{10}$ Fundada em 1610 e notável por seu patrimônio histórico, arquitetônico e cultural, a cidade de Itu é uma das mais antigas do Estado de São Paulo e ficou conhecida como "berço da República" graças às
} 
paulista, contou com o apoio da Secretaria Municipal de Cultura e do Patrimônio Histórico para a colocação, em esculturas públicas, de "máscaras de proteção facial como forma de conscientizar a população quanto à importância de seu uso" ${ }^{11}$, segundo noticiou o Jornal de Itu, em 14 de maio. "Figuras ilustres" foram selecionadas e entre elas as esculturas de: Domingos Fernandes, na Praça de Independência; Padre Bartolomeu Taddei, na Praça José de Anchieta; e Almeida Júnior, na praça homônima (Figura 4).

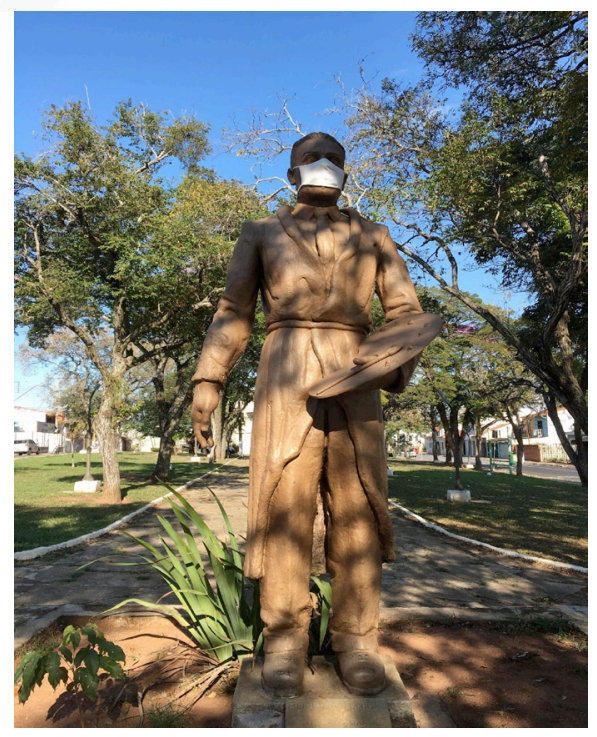

Figura 4: Almeida Júnior (1952), de Júlio Guerra, Praça Almeida Júnior, Itu, SP. Fonte: Foto Maria Cecília França Lourenço, jul. 2020.

Natural de Itu, a noticiada "figura ilustre" de José Ferraz de Almeida Jr. é novamente lembrada, quando sua imagem se torna veículo de mensagem fundamental pela vida

articulações entre políticos e fazendeiros locais, descontentes com o Governo Imperial, e a formação da Convenção Republicana de Itu (1873), cuja história encontra-se fartamente documentada no palco dessa primeira convenção brasileira, o Museu Republicano. Um conjunto de igrejas constitui importante patrimônio histórico e arquitetônico, entre elas a Igreja Nossa Senhora da Candelária ou Igreja da Matriz (1780), tombada pelo Iphan em 1938, com altar principal barroco e o teto pintado por Frei Jesuíno de Monte Carmelo (1764-1819) e algumas telas de teor sacro por José Ferraz de Almeida Júnior (1850-1899).

${ }^{11}$ Desde 12/05/2020 o Governo do Estado de São Paulo instituiu o uso obrigatório de máscaras em ambientes fechados sob pena de multa, como forma de proteção contra a pandemia da Covid-19 desafiando um veto do Governo Federal derrubado apenas em 19/08/2020. 
dos cidadãos ituanos. Esta mesma imagem é sintoma do monumento ${ }^{12}$ em tributo ao filho da terra e durante anos esteve recolhida ao depósito municipal, após ter integrado um conjunto escultórico resultado de concurso público vencido por Júlio Guerra (1912-2001). Um arco do triunfo com mais de quatro metros de altura, revestido em granito rosa, pedra originada na região, completado com inscrições nos dois frontispícios, "José Ferraz de Almeida Júnior, 1850-1899" e "Paulista na sensibilidade, brasileiro no gênio e universal na arte", em letras garrafais. Completavam a composição, a estátua com 2,20 metros, em bronze, postada à frente de uma das colunas e placas simulando as pinturas com motivos sobre o homem e a vida caipira que notabilizaram o homenageado (FATORELLI, 2018, Blogspot).

\section{BORBA GATO: A SAGA CONTINUA}

Outro monumento de autoria de Júlio Guerra é uma celebração tardia ao IV Centenário de Santo Amaro (1960) que focaliza a liderança e heroicidade bandeirista, localizado na confluência da Avenida Santo Amaro com a Adolfo Pinheiro, atualmente integra o Inventário de Obras de Arte em Logradouros Públicos da Cidade de São Paulo, mantido pelo Departamento do Patrimônio Histórico. Retrata Manuel de Borba Gato (1649-1718), o bandeirante cuja estátua simula, por sua postura hierática, a de um guardião às portas do bairro habitado por seus descendentes, é uma figura imperativa, seja pelo motivo representado ou por conferir aura ao lugar (Figura 5).

\footnotetext{
${ }^{12}$ Erigido na Praça da Independência (Largo do Carmo) entre 1952 e 1955, o monumento foi retirado pela gestão municipal posterior em 1956. Na década de 1970, quando localizada, a estátua em bronze foi implantada na Praça Almeida Júnior, Vila Nova, encontra-se identificada por placa providenciada por familiares de Júlio Guerra, com os dizeres: "Muito há em que se fazer, para que seja preservada e divulgada uma obra, pois a produção história é dinâmica e necessita de uma 'arqueologia' constante em nome da historiografia, mesmo que essa busca incessante resulte em um pequeno fragmento, um dia há de chegar perto de um todo, jamais será o final, mas apenas concretizar uma finalidade!" (FATORELLI, 2018, Blogspot).
} 


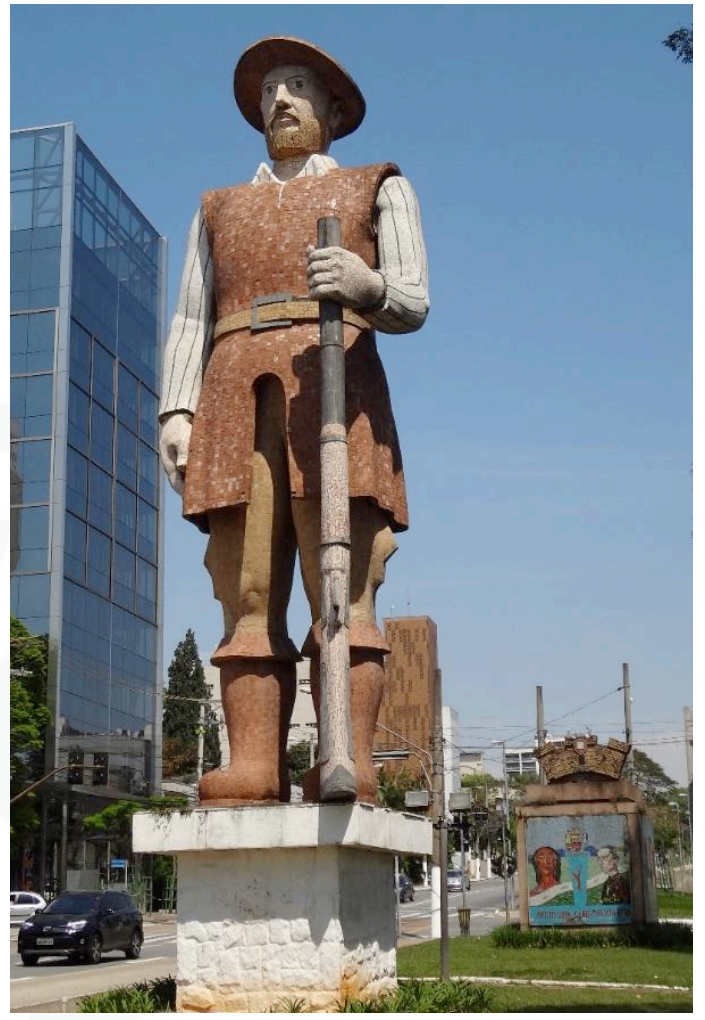

Figura 5: Borba Gato (1962), Júlio Guerra. Santo Amaro, São Paulo, SP. Fonte: Foto da autora, ago. 2020.

A obra Borba Gato (1962) foi criada pelo artista natural da então cidade de Santo Amaro premiado recorrentemente, de 1941 a 1966, no Salão Paulista de Arte Moderna, construída em concreto e revestida na técnica de mosaico composto por pequenas pedras de basalto e mármore que introduzem um novo conceito de colorir a cidade. Pesando 40 toneladas e medindo quase 13 metros de altura, inclui um pedestal que a eleva do solo, característica das esculturas urbanas do autor. Outra de suas marcas é incorporar ao tema textos e imagens secundárias, mas não menos importantes, compondo a representação principal do monumento.

Assim, na mesma praça triangular, a poucos metros da figura bandeirante, o escultor posicionou um grande cubo em cujas faces laterais repousam quatro coloridos mosaicos celebratórios. Neles as homenagens se dividem entre a fundação de São Paulo, nas figuras de Caiubi e Anchieta, a imigração alemã e seu pioneirismo industrial, os doadores de fundos para a construção da Capela de Santo Amaro, o educador jesuíta Belchior de Pontes e o poeta Paulo Eiró (Figuras 1, 2, 3, 4). A obra 
catalisa no motivo as ideias e convicções de um dado grupo santamarense, construindo um discurso e falando em nome de todos os habitantes do populoso bairro da Zona Sul paulistana, pela voz do maior panegirista local (Figura 6).
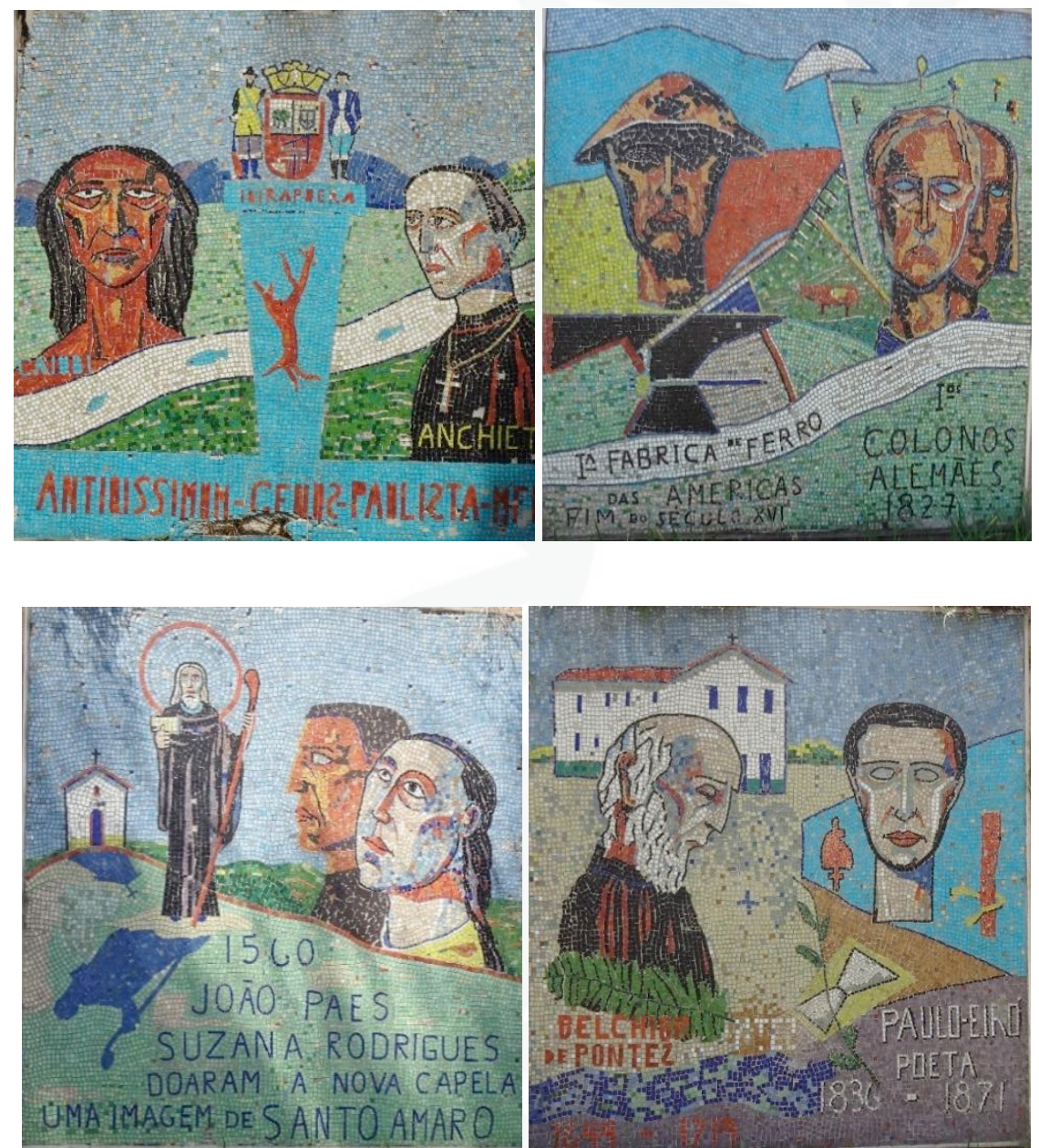

Figura 7: Mosaicos, det. Borba Gato (1962), Júlio Guerra. Santo Amaro, São Paulo, SP. Fonte: Foto da autora, ago. 2020.

Com orgulho, Júlio Guerra discorreu sobre os inúmeros tributos prestados em entrevistas concedidas à autora ${ }^{13}$, quando delicadamente dispôs para pesquisa documentos e escritos pessoais, bem como seu acervo artístico constituído de

\footnotetext{
${ }^{13}$ No ano de 1993, enquanto pesquisava $A$ escultura moderna brasileira nos acervos museológicos paulistanos (1991-3), na FAUUSP, sob a coordenação da profa. dra. Maria Cecília França Lourenço, a autora teve a oportunidade de coletar dados e opiniões do artista plástico Júlio Guerra que geraram o artigo A monumentalidade na obra de Júlio Guerra, para a Pinacoteca do Estado de São Paulo, e o vídeo Júlio Guerra: monumentos urbanos, depositado na biblioteca da FAUUSP, ambos divulgados em 1994.
} 
inúmeras pinturas de paisagens e cenas cotidianas, retratos, bustos e estátuas de personagens locais, corroborando a explicação dos convites para integrar, com suas obras, alguns dos edifícios mais marcantes na área ${ }^{14}$.

Em sua simplicidade Guerra confessou que "arte a gente faz para a gente e gente como a gente" $^{15}$, talvez para justificar a identificação de si mesmo como amador, mas certamente minimizando a visibilidade que "sua arte" adquire a cada novo monumento seu implantado na cidade. Tem origem nessa mesma simplicidade sua maior contribuição, já que imbuído do projeto de ser um "artista amador", legou rastros do operário na expressão da pincelada ingênua nos quadros e dos movimentos manuais no barro que modelava marcando indelevelmente, pintura e escultura, como sintoma "de uma mesma atitude básica, discernível em todas as outras qualidades de seu estilo", conforme identifica Erwin Panofsky (1986, p. 22), para explicar o que chamou de significado intrínseco ou conteúdo em seus Estudos de iconologia.

Significado esse que o mesmo autor afirma constituir o mundo dos valores simbólicos contidos na história dos sintomas culturais e sobre os quais DidiHuberman interpõe a questão da insuficiência do que seria o método panofskyano para a análise das imagens da arte que escapam das problemáticas do visual "tirania do visível" - e do figurável - "tirania do legível" (2020, p. 16). Opõe-se, ainda, à distinção dada, em meados do século $\mathrm{XX}$, entre os mundos de significação $e$ representação pelo historiador alemão, afirmando que "há somente representação" pois "o símbolo precede e inventa a realidade" (p. 134). No caso da figura soberana do bandeirante, aqui em questão, o próprio símbolo determina as escolhas do artista: escala, posição da implantação, matéria.

Essas escolhas, simultaneamente, trazem monumentalidade e a inserem na memória coletiva. A primeira contribui para a expressão da própria obra por ampliar sua visibilidade tornando-a marcante, seja pela grandiosidade volumétrica, seja pela

\footnotetext{
${ }^{14}$ Iguatinga (1950) disposta no hall de entrada da Biblioteca Paulo Eiró, o mural de 18m em frente ao Teatro Paulo Eiró (1968), a estátua de S. Paulo Tecelão implantado no Largo Los Andes, duas esculturas tumulares no Cemitério de Santo Amaro: Cristo com a Virgem Maria e Cristo com Maria Madalena.

${ }^{15}$ Depoimento prestado por Júlio Guerra em entrevista à autora (1993).
} 
postura impositiva dada à imagem, explicitada por Erwin Panofsky, desde 1932, quanto à análise crítica da imagem afirmando que "todo objeto e todo fenômeno visíveis já trazem sua consequência interpretativa" (DIDI-HUBERMAN, 2020, p. 135). Por sua vez, a segunda trabalha a identificação com o discurso proposto e, embora este discurso esteja dado, inerente à figura bandeirante, as pessoas e a sociedade são dinâmicas e, portanto, identidades individuais e coletivas são móveis.

É exatamente na construção de uma nova memorialidade que, em diferentes oportunidades, grupos se constituem e pedem a derrubada do Borba Gato. Alguns ficam no terreno dos julgamentos, falam de seu aspecto monstruoso, isto é, julgaram-no um monumento ao mau gosto. Talvez isso se deva à aparência telúrica, vulgarmente dita grotesca, ou talvez porque suas preferências se alinhem às técnicas tradicionais, bronze e pedra, que povoam a cidade. Há, porém, críticas à própria existência do marco, ou seja, o culto à figura histórica que dizimou os povos originários brasileiros, e, na atual cena da derrubada das estátuas, pedem o extermínio de toda e qualquer figura escravagista, genocida, colonizadora das ruas, praças, parques, manifestando o desejo de se reconhecerem nesses lugares.

\section{MÃe Preta e o GRANDE ABRAÇO}

"Na escravidão do amor, a criar filhos alheios, / rasgou, qual pelicano, as maternais entranhas / e deu à Pátria Livre, em holocausto, os seios!" (COSTA, s.d.)

Igualmente assinada por Júlio Guerra, se destaca no espaço urbano paulistano a escultura da Mãe Preta (1955), implantada no Largo Paissandu, ao lado da Igreja de Nossa Sra. do Rosário dos Homens Pretos ${ }^{16}$, erigida por mão de obra composta exclusivamente por homens pretos e inaugurada em 1908. Já o monumento,

\footnotetext{
${ }^{16}$ A Igreja de Nossa Senhora do Rosário dos Homens Pretos foi construída entre 1904 e 1906, sendo logo consagrada após uma procissão da Irmandade dos Homens Pretos, acompanhada de banda, ter transladado a estátua de Maria desde a antiga Igreja do Rosário, situada no Largo do Rosário, atual Praça Antonio Prado, nome do prefeito da cidade (1899-1911) à época das transformações urbanísticas na região, responsáveis pela derrubada da capela e a consequente expulsão da Irmandade.
} 
vencedor de concurso público promovido pela prefeitura, em 1953, para celebração do IV Centenário da Cidade de São Paulo (1954), só foi inserido na paisagem em janeiro do ano seguinte. Trata-se de um peça de bronze medindo 2,20 x 2,60 x 1,60 metros com um pedestal revestido de granito com 1,44 x 2,97 x 1,80 metros, no qual, além de desenhos com referência à casa grande, à senzala e aos castigos aplicados aos escravos, traz inscritos na parte frontal, aos pés da estátua, versos do poema “Mãe Preta", de Ciro Costa (1879-1937):

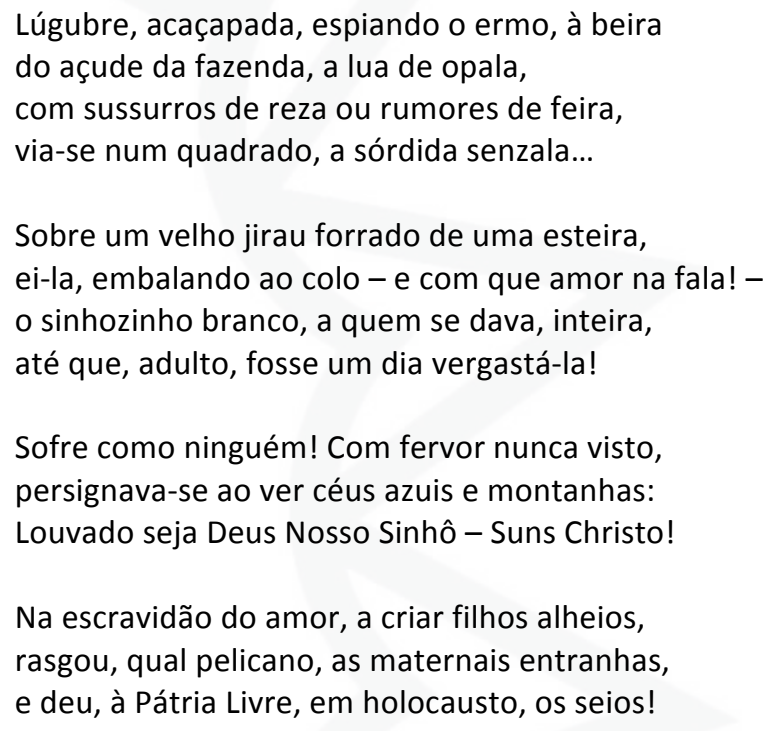

O lugar de inserção desta obra logo se tornou um espaço de luta e resistência dos afrobrasileiros, que ali passaram a celebrar as datas relacionadas à nomeada libertação dos escravos, em 13 de maio, dia da assinatura da Lei Áurea (1888), e mais tarde à Consciência Negra, em 20 de novembro, dia da morte de Zumbi dos Palmares (16551695), e também a realizar ritos sincréticos, incorporando rituais afro e católicos, expandindo as atividades de dentro para fora das paredes do templo. Muito além dessas comemorações o Largo se transformou numa área participativa e acolhedora, abrigando manifestações artísticas e religiosas que não tardaram a agregar a figura daquela mulher negra amamentando a criança branca. Apesar da indubitável rememoração dos tempos da escravatura, a imagem recebe oferendas durante todo o ano, são flores, velas, comidas, bilhetes com pedidos e agradecimentos vindos de mulheres e homens pretos que a têm como entidade religiosa. 
Miriam Escobar, em seu livro Escultura no espaço público em São Paulo, observa, na "relação espacial mais complexa que envolve a percepção visual, que tangencia a todo instante a experiência individual e coletiva, em sua abrangência cultural e histórica", que a implantação faz da escultura o "sujeito no espaço público" (p. 23). Tal afirmação remete à apresentabilidade da imagem na qual "nossos olhares pousam antes mesmo que nossa curiosidade - ou vontade de saber - passe a se exercer" (DIDI-HUBERMAN, 2020, p. 16).

Por outro lado, Escobar afirma que "esta obra marca, através do tema étnico, a figura das amas de leite, valorizando a raça e o sentimento coletivo" (1998, p. 67), levantando questões polêmicas quanto à classificação do tema e ao imputar valorização racial ao papel ali representado. O primeiro fator leva a uma discordância de ordem antropológica na expressão "tema étnico", que incluiria o pertencimento a determinado grupo sociocultural - refletida principalmente na língua, religião e costumes -, opondo-se às diversas origens dos povos d'África ${ }^{17}$ escravizados e trazidos ao Brasil pelos portugueses. Quanto à eleição da "figura das amas de leite" que a cultura eurocêntrica faz ver como reconhecimento ao gesto de carinho, na opinião dos grupos afro-brasileiros, trata-se de tornar memorável um dos papéis impingidos às escravas e que eles gostariam de apagar, a subserviência (Figura7) ${ }^{18}$.

\footnotetext{
${ }^{17}$ Darcy Ribeiro, em O povo brasileiro (1995), distingue os negros do Brasil - os afro-brasileiros - em três grandes grupos e, portanto, dotados de notável "diversidade linguística e cultural": culturas sudanesas, culturas africanas islamizadas e tribos Bantu do grupo congo-angolês (RIBEIRO, 2006, p. 102-3).

${ }^{18}$ Impossibilitada de fotografar a estátua da Mãe preta, graças à interdição da área do Largo Paissandu pela Prefeitura para oferecer apoio sanitário aos moradores de rua em época de pandemia, a autora teve que recorrer ao Wikimedia para obtenção da imagem identificada por Figura 7.
} 


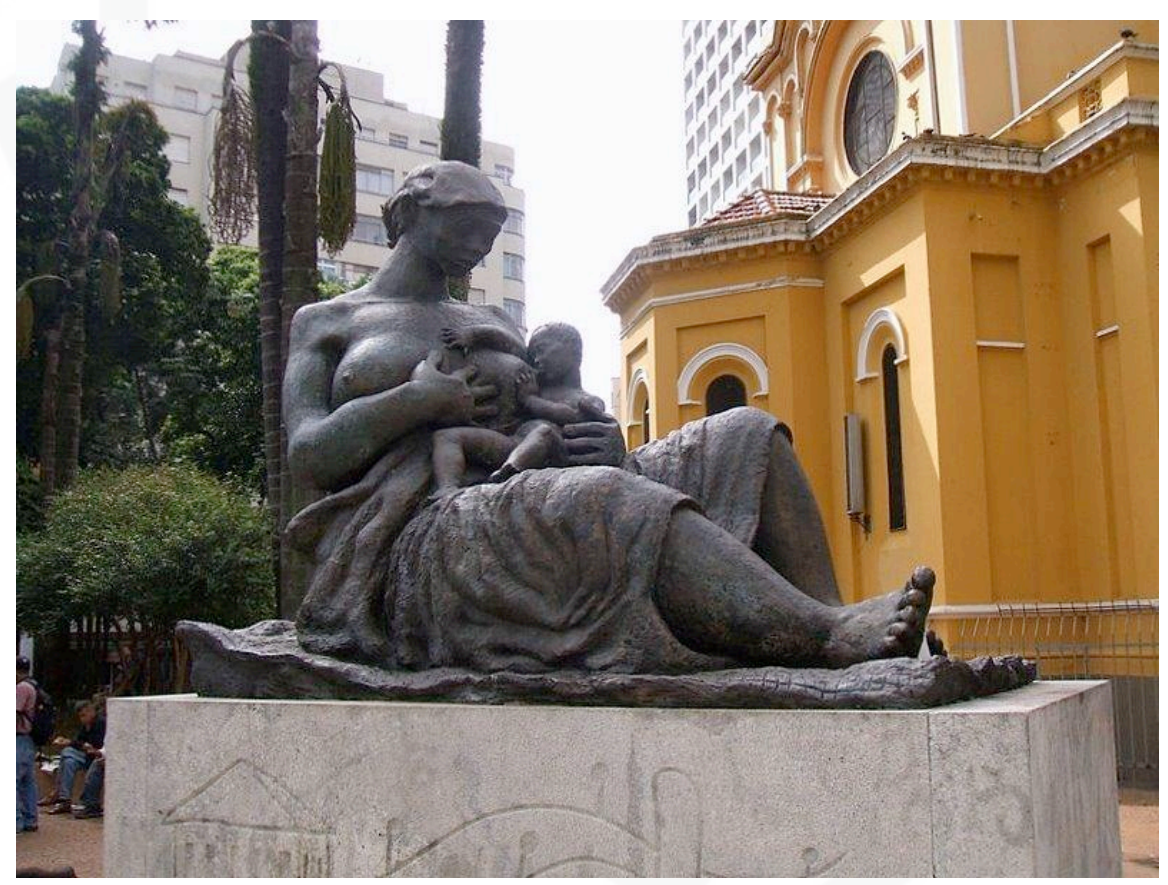

Figura 7: Mãe Preta (1955), Júlio Guerra. Largo do Paissandu, São Paulo, SP. Fonte: Wikimedia, 27 set. 2020.

Porém, essa mesma síntese simbólica individualiza a manifestação e gera o discurso poético ao qual coube retratar com força retórica uma imagem caracterizada pela altivez, a despeito da sua condição, dos trajes despojados e da postura nada formal sobre o volumoso pedestal. Paradoxalmente, é graças ao enorme prisma e suas linhas geométricas precisas, em contraste com os contornos femininos ao mesmo tempo lânguidos e enérgicos, que se percebe o levitar da figura, similar às representações na iconografia católica para divindades ou seres santificados. A potência desse monumento também se revela nas ilustrações gravadas na sua base, que transcrevem cenas e objetos relacionados à condição de confinamento e castigo na escravidão, integrando a imagem ao universo terreno. Estas impressões rasgam a superfície porosa da pedra, marcando-a indelevelmente e denunciando a violência temática que redimem Júlio Guerra das acusações a ele imputadas.

Juntos, tais elementos visuais somados à integração do tema e do lugar, talvez expliquem o acolhimento da obra pela comunidade, levando a Irmandade do Rosário dos Homens Pretos a encaminhar o pedido para o tombamento do Monumento à mãe preta pelo CONPRESP/Conselho Municipal de Preservação do Patrimônio 
Histórico, Cultural e Ambiental da Cidade de São Paulo, que aceitou em 2004 reconhecer seu valor cultural para a cidade de São Paulo. 0 reconhecimento do órgão público à demanda da população e, em particular dos movimentos negros, garante a manutenção do bem patrimonial, tanto física quanto geograficamente, graças à qual essa mesma comunidade promove sua permanência.

A inclusão do Monumento à mãe preta nos bens patrimoniais da cidade garante oficialmente sua condição de conservação e fixação no Largo Paissandu, tornando, portanto, ilegais quaisquer especulações a respeito da derrubada ou do deslocamento que o destitui simbolicamente. Centro de reverências nas festividades negras já mencionadas, a imagem também é idolatrada com oferendas o ano todo e em duas datas especiais, quando é cercada por bandeirolas nas festas juninas e flores no dia das mães. $\mathrm{O}$ abraço da comunidade resulta, indubitavelmente, do sistema de simbologias inerente à representação, que vai além das figuras eleitas por Júlio Guerra, são sinais - símbolo e sintoma - identificados por Erwin Panofsky, nos anos 1930, como expressões das "tendências gerais e essenciais do espírito humano" nos temas e conceitos específicos (DIDI-HUBERMAN, 2020, p. 234).

Antes mesmo, conforme escreve Georges Didi-Huberman, "foi com o sonho e o sintoma que Freud rompeu a caixa da representação. Foi com eles que abriu, isto é, rasgou e livrou, a noção de imagem", apontando para o fato de que esses conceitos já estavam lançados no livro $A$ interpretação dos sonhos (1900), quando fixava no "valor de deformação e no jogo das rupturas lógicas que atinge com frequência o 'espetáculo' do sonho como uma chuva perfurante” (2020, p. 191). Algo contundente e de efeito contínuo se passa com a imagem, a mantém viva, mas também nos move. Didi-Huberman sobrevoa a problemática freudiana como forma de traduzir a invenção dos "valores simbólicos inusitados, de traços singulares que nada permitia prever" e se opõem às certezas do pensamento clássico (p. 196-7).

Assim a representação será como que partida em camadas, o afeto da representação e o afeto de si mesmo: como se o trabalho do sonho fosse movido pelo propósito paradoxal de uma visualidade que ao mesmo tempo se impõe, nos perturba, insiste e nos persegue - na medida mesmo em que não sabemos o que nela nos perturba, de que perturbação se trata e o que isso pode de fato significar... (DIDI-HUBERMAN, 2020, p. 196) 


\section{CONSIDERAÇÕES FINAIS}

A força das manifestações sobre a derrubada das estátuas não é menor nem mais significativa que os gritos pela própria sobrevivência das gentes, emanados das concentrações deflagradas nos últimos meses. É mais uma das demandas populares e não deve ser ignorada. Tivemos a oportunidade de ler, ouvir e assistir às mais diversas falas sobre o assunto. Vale dizer que muitos defendem o status quo por apego àquilo que está posto, porque já se acostumaram à presença dessas esculturas e, mais ainda, por concordarem com os valores ali propostos. Uns contra outros a favor da eliminação, e há aqueles mais criteriosos que tecem considerações sobre o tema justificando sua posição e fazendo sugestões. Identificada com estes últimos, resolvi transformar em artigo minhas ponderações, elegendo conjunto memoriais denunciados nessas mesmas manifestações e fatos recorrentes envolvendo atos de ocupação e apropriação dos monumentos públicos na cidade de São Paulo.

Posiciono-me a favor da memorialidade e uno-me aos atores dos protestos contra as imposições, discriminações, intolerâncias que vêm animando certos grupos extremistas. Posiciono-me contra as radicalidades enquanto postura dual, que opõe, que separa, e a favor das radicalidades enquanto busca das raízes originárias, do que nos dá suporte e constitui. Posiciono-me apoiando as maiorias minorizadas pelo sistema de privilégios instaurado pela hegemonia dos bens de capital. Posiciono-me, portanto, a favor das insurgências aqui relatadas e das muitas mais que virão. Impossível calar diante de tanta turbulência. Sim, mesmo um simples artigo deve ser um ato político. É nessa condição de um ser político que pesquiso e divulgo meus estudos.

Impactada pelo recolhimento obrigatório, devido à pandemia, acompanho à distância os acontecimentos, mas é impossível ignorar os apelos das ruas e deixar de unir forças. A ligação com os espaços públicos paulistanos vem das pesquisas sobre o patrimônio artístico da capital paulista, a focar principalmente na memória e espacialidade, que construíram os parâmetros de conhecimento da implantação, de acolhimento, de perenização. Desta maneira, os tributos escultóricos aqui selecionados envolveram questões da contratação, execução, localização, 
apresentação e representação fundamentais para a explanação dos pensamentos e das ideias de manutenção ou não dessas obras.

Quanto às homenagens aos bandeirantes, minha primeira sugestão, para as peças de menor porte, é o translado para o Museu Paulista, reunindo-as a outras inúmeras elegias - desenhos, bustos, pinturas, estátuas - abrigadas no acervo. A mesma instituição criaria, então, um trabalho para detalhar a história de cada personagem desses tributos, atualizando dados e feitos, nos termos conformados pela nova historiografia, ressignificando o papel desses paulistas na formação do Brasil. Tais atos podem ser complementados pela substituição daquelas por outras que "recuperem" as identidades de grupos indígenas e/ou afro.

Para as de maior porte - incluindo particularmente o Borba Gato e o Monumento às Bandeiras, aqui mencionados - indicaria a manutenção nas áreas, desde que sejam intensificadas e atualizadas as informações a respeito da violência desses colonizadores. Que se divulgue, por exemplo, seu comportamento como caçadores de escravos, quando conquistavam determinado espaço não os povoando, ao contrário, destruindo aldeias, vilas e até cidades -, além de dizimarem diversos povos originários brasileiros com requintes de crueldade. Essa vivificação promoveria um novo interesse, agora "atualizado" e ressignificado, impedindo que continuem a materializar representações "passadas", premeditadamente construídas e objetivadas.

Proponho uma campanha de divulgação nacional, pela maior diversidade de meios possível, e que se responsabilize por desconstruir a idealização desses homens que povoam o imaginário dos brasileiros e dos países da América do Sul, associando os "paulistas" a esses implacáveis dominadores e exterminadores. Que as informações sejam individualizadas - referindo-se à figura celebrada e seus atos indignos -, que não se restrinjam a minúsculas placas ao lado ou aos pés de cada estátua. Para que não esqueçamos jamais, sugiro que os conteúdos sejam divulgados - tanto física, quanto digitalmente - em guias do bairro e da cidade, nas visitas educativas e turísticas, nos livros de História do Brasil.

Por outro lado, a despeito de simbolizar o papel de submissão da mulher escrava, o caso da escultura da Mãe Preta ganha novos atributos, a ela incorporados pela própria 
comunidade e, em especial, por entidades constituídas de mulheres e homens pretos que se reúnem no mesmo largo. A ela veneram e fazem oferendas, demonstrando um respeito que sincretiza ritos afro e católicos depositam a seus pés velas, flores e bilhetes (quase ex-votos). Sua presença maciça impera qual rainha postada sobre um pedestal que a suspende e leva inscrições sobre a vida vivida e eternizada no gesto maternal, um gesto que a humaniza e a faz superior aos seus algozes.

Como se sabe, embora Júlio Guerra tenha escolhido o motivo artístico adequado ao concurso para o monumento do Largo Paissandu, o caráter simbólico hoje imanente foi construído na recepção popular que a seu lado celebra a alforria desejada. Uma emancipação que Ihes foi negada mesmo após a assinatura da lei, mas que não esmoreceu, e não esmorece, sua luta contra a discriminação social e racial impostas até nossos dias. $\mathrm{O}$ grande testemunho do não abrandamento dessa gente ficou patente na batalha pelo tombamento, como patrimônio público paulistano, dessa figura que chamam de "mãe". Que a conquista recente brote fulgurante do documento oficial e não fique só no papel como o da libertação dos escravos!

\section{REFERÊNCIAS BIBLIOGRÁFICAS}

ATHIAS, Renato. Diversidade étnica, direitos indígenas e políticas públicas. Recife: NEPE; UFPE; 2005.

CONDEPHAAT, Bens tombados 1968-1998. Coord. Edna Hiroe Miguita Kamide, Tereza Cristina Rodrigues, Epitácio Pereira. São Paulo: Imprensa Oficial do Estado; 1998.

DIDI-HUBERMAN, Georges. Diante da imagem: Questão colocada aos fins de uma história da arte. Tradução Paulo Neves. São Paulo: Editora 34; 2020.

. Diante do tempo: História da Arte e o anacronismo das imagens. Belo Horizonte: UFMG; 2015.

. A imagem sobrevivente: História da Arte e tempo dos fantasmas segundo Aby Warburg. Rio de Janeiro: Editora Contraponto; 2013.

Que emoção! Que emoção? São Paulo: Editora 34; 2013.

ESCOBAR, Miriam. Escultura no espaço público em São Paulo. São Paulo: Secretaria Municipal de Cultura da Prefeitura de São Paulo; Vega Engenharia Ambiental S/A; 1998. 
KEATING, Vallandro; MARANHÃO, Ricardo. Caminhos da conquista: a formação do espaço brasileiro. São Paulo: Editora Terceiro Nome; 2008.

LE GOFF, Jacques. História e memória. Tradução Bernardo Leitão et alii. Campinas: Editora da UNICAMP; 1990.

PANOFSKY, Erwin. Estudos de iconologia: temas humanísticos na arte do Renascimento. Lisboa: Editorial Estampa; 1986.

PECCININI, Daisy. Brecheret: a linguagem das formas. São Paulo: Instituto Victor Brecheret; 2004.

RIBEIRO, Darcy. O povo brasileiro: a formação e o sentido do Brasil. São Paulo: Companhia das Letras; 2006.

\section{Fontes eletrônicas e sites}

ESTÁTUA de Jen Reid. Bristol, Inglaterra, 7 jun. 2020. Foto Alex Richards. Disponível em: https://pt.wikipedia.org/wiki/Ficheiro:A_Surge_of_Power_(Jen_Reid)_15th_Jul y_2020.jpg. Acesso em: 27 set. 2020.

FATORELLI, Carlos. Júlio Guerra e a Obra de Almeida Júnior em Itu, São Paulo. Blogspot.com.br, 18/ 05/2018. Disponível em: http://carlosfatorelli27013.blogspot.com/2018/05/julio-guerra-e-obra-dealmeida-junior.html. Acesso em: 02 set. 2020.

MONUMENTO à Mãe Preta (1955), Júlio Guerra. Largo do Paissandu, São Paulo, SP. Disponível em: https://commons.wikimedia.org/wiki/File:Julio_Guerra__M\%C3\%A3e_Preta_(Pai\%C3\%A7andu).JPG. Acesso em: 27 set. 2020

Disponível em: https://www.prefeitura.sp.gov.br/cidade/secretarias/cultura/patrimonio_histo rico/adote_obra/index.php?p=8291. Acesso em: 20 ago. 2020.

Disponível em: https://www.al.sp.gov.br/noticia/?id=280997. Acesso em: 21 ago. 2020.

MONUMENTOS coloniais em tempos pós-coloniais: o Monumento a Mouzinho de Albuquerque após o fim do Império, s. a. Paper-Cloud. IV Congresso de História da Arte Portuguesa. Lisboa: Universidade Nova de Lisboa; Fundação Calouste Gulbenkian, 21-24/11/2012, publicado em 26-10-2017. Disponível em: http://www.paper-cloud.net/archive/post/2012-monumentos-coloniaistempos-pos-coloniais-chap/. Acesso em: 01 set. 2020.

O QUE fazer em Itu. Disponível em: https://saopaulosemmesmice.com.br/o-quefazer-em-itu/. Acesso em: 16 ago. 2020. 
RAHME, Anna Maria Abrão Khoury. Configurações Paulistas: operando a saga bandeirante, p. 77-108. Revista ARA, set. 2018. Disponível em: https://www.revistas.usp.br/revistaara/article/view/150923/148298. Acesso em: 16 ago. 2020.

JÚLIO GUERRA. Disponível em: https://santoamarocultural.wordpress.com/julioguerra-o-mestre/. Acesso em: 16 ago. 2020.

Disponível em: http://carlosfatorelli27013.blogspot.com/2012/09/julio-guerraprofissional-amador.html. Acesso em: 02 set. 2020. 